\title{
The Use of Literature and Literary Texts in the EFL Classroom; Between Consensus and Controversy
}

\author{
Jelena Bobkina \\ English I UCM, Ciudad Universitaria s/n 28040, Madrid, Spain \\ E-mail: jbobkina@filol.ucm.es \\ Elena Dominguez (Corresponding author) \\ English I UCM, Ciudad Universitaria s/n 28040, Madrid, Spain \\ E-mail: elenadominguez@filol.ucm.es
}

Received: 25-11-2013

doi:10.7575/aiac.ijalel.v.3n.2p.248
Accepted: 03-01-2014

Published: 01-03-2014

\begin{abstract}
This article provides a review of ideas and research regarding the role of literature in the EFL university classroom. After a brief historical overview of the question of using literature in the language classroom, the article discusses the reasons for the demise and resurrection of literature as an input for language classes. Right after that, the article deals with advantages and drawbacks of using literary texts as language tools by means of drawing on recent ideas on language teaching practice and theories. Finally, in a practical move, this paper depicts the past and current approaches to teaching literature in language teaching classes.
\end{abstract}

Keywords: Literature; Curriculum; EFL; Higher Education

\section{Introduction}

The last twenty years have been clearly marked by an explosion of work in literary and cultural theory, providing a strong basis for further research on the relationship between literature, language and education. Thus, a whole new paradigm involving the integration of language and culture, being literature a part of culture, emerged in the late 80 -s and has developed throughout the 90 -s.

Not surprisingly, in recent years, there has been a strong move towards the study of literature, mainly as culture, and its reintegration into the academic curriculum. Therefore, many researches claim the need to include literary texts into the L2 curriculum (Cook, 1994; Shanahan, 1997; Hanauer, 2001; Carroli, 2008) or alternatively advocate a content-based curriculum that would include literature components (Liddicoat, 2000; Kramsch, 2013).

Many language teachers tend to admit the potentiality of literary texts in terms of development of different aspects of a foreign language. It is argued that literature promotes, among others, students' L2 vocabulary knowledge, knowledge of lexical phrases and fixed expressions (Frantzen, 2002; MacKenzie, 2000), grammatical knowledge (Tayebipour, 2009), language awareness (Carroli, 2008), and sociolinguistic and pragmatic competences (McKay, 2001). Also, emphasis on reading, particularly the reading of culturally authentic texts, has become one of the central claims for curriculum reform in EFL teaching (Swaffar, 1999; Arens \& Swaffar, 2000; Dupuy, 2000).

The latest developments of text-based teaching also recommend a curriculum "in which language, culture, and literature are taught as a continuum" (Foreign Languages and Higher Education: New Structures for a Changed World, 2007). In this sense, recent studies indicate the undeniable benefits of literary texts as an important part of the EFL programs despite the fact that their use might be proved to be highly demanding for teachers and students (Rice,1991; Lima, 2010; Van, 2009). Thus for Van (2009), the study of literature is a must as far as it exposes students to meaningful contexts rich in descriptive language and interesting characters.

Despite the fact that many teachers nowadays agree on the need to reintegrate literature in the L2 curriculum, defending its reincorporation into the language classroom, literature still has to carve a niche for itself in mainstream language teaching materials (Lima, 2010). Those teachers who try to incorporate literature in the classroom inevitably find themselves facing serious problems that include key factors as lack of preparation in the area of literature teaching in EFL, absence of clear objectives defining the role of literature and a lack of the necessary background knowledge and training in literature, or shortage of pedagogically-well-designed materials (Lima, 2010; Khatib \& Nourzadeh, 2011; Edmonson, 1997). Besides, issues regarding text selection and literature syllabus and curriculum development are still much present nowadays, especially in the context of English as a global language (Carter, 2007). Last, but not least are the questions of how literature can be integrated for the benefit of students and what the most effective procedures are for its integration into the language classroom.

These premises considered, the present study is aimed at reviewing ideas and research regarding the role of literature in the EFL classroom, as well as at describing the most recent approaches in teaching literature in the language classroom. 
We also hope that the paper will help language teachers to choose the most appropriate way to incorporate literature texts in the language classroom, as well as to maximize the efficacy of their literary materials.

With this intention in mind, the paper has been divided into four main sections. After a brief historical overview of the question of using literature in the language classroom, the second and the third sections of the paper deal with advantages and drawbacks of using literary texts as language tools. Different teaching approaches to literary texts are discussed in the fourth section. Finally, the article presents some pedagogically intended conclusions and recommendations.

\section{The use of literature in the language classroom: a brief historical overview}

English and American literature have been part of the non-English speaking countries curriculum for more than 100 years now, always playing a major part in the English language syllabus (Stern, 1985). Learning a foreign language in the early part of the $20^{\text {th }}$ century, as Kramsch and Kramsch (2000) claim, often meant a close study of the canonical literature in that language. Thus literature was a key element in the Grammar Translation Method. Literary texts in the target language were used as examples of good writing and "illustrations of the grammatical rules" (Duff, 1990: 3). The focus of this teaching method was on mastering grammar structures and vocabulary. There was neither literary interest nor interest on content.

Unfortunately, after the grammar-translation method fell in disuse in the mid part of the $20^{\text {th }}$ century, a consistent rejection to the use of literature in the language classroom became the rule. The language teaching method based on the translation of Classic texts resulted rather inefficient when applied to teaching modern languages and, as a result, the tendency at the time was to eliminate literary texts from language classes to focus on teaching language skills mainly. In fact, from the $40 \mathrm{~s}$ to the $60 \mathrm{~s}$, literature disappeared from the language learning curriculum (Carter, 2007). This is how linguistics became the focal point of the language programs (Widdowson, 1982).

The first half of the 1960s represents a turning point in this sense. The issue of teaching language through literature first came out at the King's College conference on education held in Cambridge in 1963. The importance of literary texts as a useful tool in the language teaching / learning process was highlighted in this conference while the traditional approach was called into question for its incapacity to develop language skills and communicative abilities. Despite these efforts, the use of literary texts in the language classroom has remained ignored for a number of years. Almost no research on the topic of literature as a language teaching tool was carried out from the mid 1960s to the 1980s. Structural approaches to language teaching relegated literature to oblivion, as an old-fashioned tool, while the functional-notional method ignored literature as far as it lacked a communicative function (Llach, 2007). Hence Topping (1968) supported the complete exclusion of literature from the foreign language curriculum addressing its structural complexity and its nonconformity to the standard grammar rules. According to the author, literature did not seem to contribute to foreign language students in their achievement of linguistic proficiency (Topping, 1968: 97).

The mid 1980s witnessed some changes after the public opinion got alarmed by the lack of basic content knowledge and skills detected among the students of languages (Stern, 1985). This issue gave place to an immediate need to introduce students to basic literary texts as much as "to teach the necessary strategies and study habits to enable them to undergo highly demanding reading requirements in most tertiary level courses" (Gilroy-Scott, 1983: 1) As a consequence, the need for the rehabilitation and the reintegration of literature as an integral part of the communicative language programs was clearly expressed as a long-term objective in the mid 80s. Thus Gajdusek (1988) advocates the wider use of literature in the foreign language classroom, especially for mature ESL students. At about the same time, Maley (1987, cited in Carter, R. \& Walker, R., 1989) makes a valuable distinction between i) the study of literature and ii) the use of literature as a means for language learning. As pointed by the author, the second approach is based on the conviction that literature is language in use and can therefore be exploited for language learning purposes Maley (1987, cited in Carter, R. \& Walker, R., 1989). Finally, Brumfit and Carter (1986) defend "the right use" of literature in the language classroom (Brumfit, 1986). Literature could be used in this sense as an ideal tool aimed at developing the sort of skills and offering the kind of reading experience that 'informational' texts cannot provide (Kramsch, 1993; Hess, 1999).

Nowadays, further research is being conducted in this area to demonstrate the positive results of using literature in different EFL teaching areas. Thus, much research is being done to redefine the role of culture and literature in language learning for the development of language materials, syllabi, and curriculum, as well as to describe the affective nature of the interaction between the language learner and the literature of the target language (Kramsch, 2013; Liddicoat \& Crozet, 2000; Hanauer, 2001). Another currently important field of research deals with the benefits of literary texts as an essential part of integrative language teaching (Carroli, 2008; De Blasé, 2005; Bagherkazemi \& Alemi, 2010). Multidimensional advantages of literature as a means for developing EFL skills are being explored by Alderson (2000), Kern (2000) and Hur (2005), among others.

Despite the pointed multiple advances towards the use of literature for language teaching, though, the following sections of the present paper will show that there is still no consensus among language teachers and educators on the issue of literature incorporation into the EFL classroom (Lima, 2005).

\section{Advantages of using literature in the language classroom}

As mentioned above, the incorporation of literary works written in English into the EFL curriculum has been much debated since the sixties. In fact, an important number of attempts have been made in the light of interdisciplinary and discourse analysis studies to try to justify the use of literature as a foreign language teaching tool. Not in vain, literature sharpens linguistic and cognitive skills and enhances students' understanding of the human condition (Lazar 1993: 19). 
This relevance of literature as an important tool in the holistic development of students characterizes indeed the model proposed by Horner (1983).

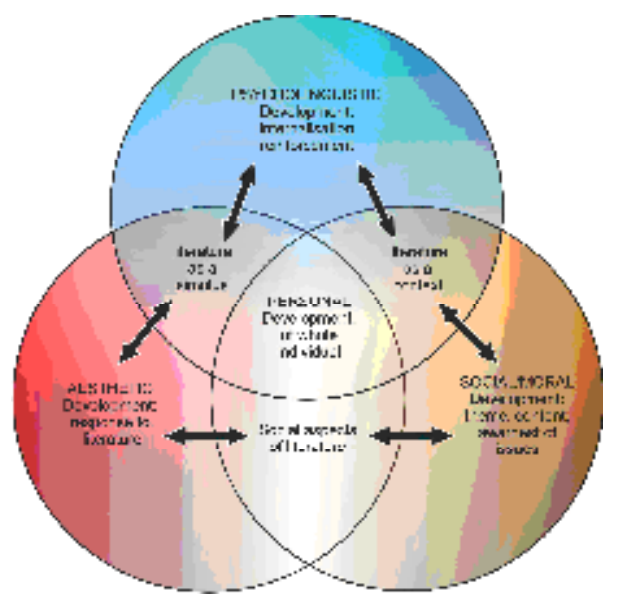

Figure 1. Adapted from Best laid plans: English teachers at work (Horner, 1983)

As shown in the graphic above, the factors supporting the introduction of literary texts into the language curriculum are organized into three big groups: aesthetic, psycholinguistic and socio-moral. The aesthetic area focuses on the students' aesthetic involvement into the reading process and the psycholinguistic area deals with the students' identification and internalization of certain behavior patterns. Meanwhile, the socio-moral area is centered on theme and content issues. Interconnected as they are, the three areas contribute to the development of the personal area that enhances the students' development as whole individuals.

Similar intentions lead Duff and Maley (1990: 6) to highlight the importance of the following criteria in support of the use of literature in the language classroom: i) linguistic, ii) methodological, and iii) motivational.

i) The linguistic criterion defends the importance of literature as a source of genuine authentic texts that provides the learner with real examples of a wide range of styles, text types and registers. Maley (1989) points in this sense that literature deals with a potpourri of language types and varieties-from slang to formal-and various subject matters. According to Collie and Slater, many genuine features of the written language such as "the formation and function of sentences, the variety of possible structures, and the different ways of connecting ideas" are presented at many levels of difficulty in literature (1987: 5). As pointed by Van (2009), literature involves a profound range of vocabulary, dialogues and prose. Working with literary texts, students are exposed to real language-originally intended for native speakers-and this allows them to become familiar with the target linguistic forms and communicative functions. Besides, the knowledge of a variety of registers, styles and genres is of primary importance as far as these language varieties are not only linguistically distinctive, but also have different social communicative functions (Kern, 2000).

ii) The methodological criterion refers to the possibility of multiple interpretations and different opinions commonly generated by literary texts. This leads students to a real, motivated interaction with the text, with their fellow students and with the teacher (Widdowson, 1982). Kern (2000) explains in this sense that literature bridges transmision of information and meaning construction. Also, it is to be considered that in the literature-based classrooms "the reader is placed in an active interactional role, working with and making sense of the (literary) language" (Brumfit, 1986:15). That is to say, the student is required to engage in "content-based purposeful learner talk in English" (Brumfit, 1986:15) and thus to be active, autonomous and central to the learning process, as well as to grow as an individual as much as in his/her relationships with the others and with the institutions (Carter, 1991:3). Meanwhile, the teacher acts as a facilitator of the learning process, aimed at helping the student to discover the meaning of the text. Students are the essential part of their own learning process, and this can hardly be achieved through the used of conventional textbooks. Literature might be the appropriate source of numerous activities for the development of reading, writing, speaking and listening skills (Belcher, 2000, Erkaya, 2005, Nasr, 2001).

iii) The motivational criterion refers to the adequacy of literary texts to the exploration of students' feelings and to the enhancement of their motivation, which is provided by authenticity and meaningful contexts (Van, 2009, Ghosn, 2002). Literary texts help "to stimulate the imagination of students, to develop their critical abilities, and to increase their emotional awareness" (Lazar, 1993: 19), as much as their pleasure in reading. The single fact of decoding the meaning of separate lexical units or phrases does not seem to be especially relevant itself. Students usually get engaged in the plot of the story, commonly feeling close to their favorite characters. This motivating engagement creates a positive general effect on the learning process which is at the same time positive for the particular process of language acquisition. 
The importance of a fourth cultural criterion as a significant factor defending the implementation of literary texts in EFL is supported by Collie and Slater (1987). Literature is probably one of the best ways to understand the culture and traditions of the target language, especially in those cases in which a visit or a stay is virtually impossible. This enables students "to understand and appreciate cultures and ideologies different from their own in time and space, and to come to perceive traditions of thought and feeling and artistic form in those cultures" (Carter, 1991: 2). This inter/cultural awareness facilitated by literature is also remarked by Van (2009) and Tayebipour (2009). Globalization, as Tayebipour (2009: 215) states, leads to a growing concern for universally shared needs. Literary texts—novels, plays, short stories, etc.-favour the understanding of the communication processes in the target language. Though representing an imaginary world, these texts often describe vivid and detailed settings and lead readers to discover the characters' personalities and worlds. This way, students learn to see the world from different points of views and discover different ways of living in different societies. They "become broadly aware of the social, political, historical, or cultural events happening in a particular society" (Floris, 2004).

Together with the four criteria mentioned above, some special virtues of learning English through literature are specified by Maley (1989). The most important ones are: i) universality, ii) non-triviality, iii) personal relevance, iv) variety, v) interest, vi) economy and suggestive power, and vii) ambiguity.

i) Universality: There is no language without oral or written literature. This includes global topics-love, death, separation, jealousy, pride, etc.- -shared by all cultures.

ii) Non-triviality: Most of the more traditional forms of language input tend to introduce language in artificial contexts that are often rejected by students. Literature, meanwhile, does not trivialize, but offers the reader genuine, authentic input.

iii) Personal relevance: Literary texts commonly deal with events, ideas, feelings and emotions that may conform to a real or imaginative part of the readers' experience. This makes it much easier for them to relate the reading experience with their previous background knowledge that facilitates the learning process.

iv) Variety: Literary texts tend to cover a wide variety of topics and to include all the conceivable varieties of the language.

v) Interest: Since the topics and themes treated in literary works are part of the global human experience, they are intrinsically interesting for readers.

vi) Imaginative power: One of the greatest strengths of literature consists in its imaginative, suggestive power, which is undoubtedly beyond the scope of the written part of the text. This makes literature an ideal tool generating topics for class debates.

vii) Ambiguity: Literature is opened to subjectivity and association of ideas and guarantees class debates.

The latest developments in the fields of sociolinguistics, pragmatics, semiotics, discourse analysis, and psycholinguistics reveal some additional benefits that can be attributed to literary texts. According to Ghosn (2002), reading literary texts fosters emotional intelligence. Khatib et al. (Khatib, Rezaei, Derakhshan, 2011) consider literature to be a good source for nurturing our Emotional Quotient. Dealing with affection, literature is also specifically related to the human ability to control emotions (Averil, 2001). Research in the field (Gajdusek, 1988, Ghosn, 2002, Van, 2009) similarly seems to describe literature as a means for critical thinking enhancement among language learners. Hence Lager (1997) states that literature helps students to reflect on their lives and their surrounding world, opening "horizons of possibility, allowing them to question, interpret, connect, and explore" (607). Also, Ghosn (2002) explains that, not taking things for granted, literature may bring changes in the attitudes towards the world.

Finally, the sociolinguistic and pragmatic components of the linguistic knowledge, considered by some scholars to be the pillars of the communicative competence model, can be successfully developed through literary texts (McKay, 2001). Thus, literature turns out to be an excellent tool to learn about the features related with appropriateness in language.

\section{Difficulties of using literature in the language classroom}

Despite the advantages of the use of literature in the language classroom which have been mentioned in the previous section of the present work, there are also some major difficulties that require further attention such as language itself, cultural issues or text selection (McKay, 2001, Savvidou, 2004, Lima, 2005). In fact, if we stop to analyze some of the most popular literary texts "we may find ourselves in the quite uncomfortable position of having to acknowledge that some of our favourite works might cause considerable inconvenience to our language students" (Lima, 2005: 186).

The most common problem is language itself, more especifically, syntax and vocabulary. Literary vocabulary and grammatical structures are often considered to be too complicated, making reading a highly demanding activity. McKay (2001) and Savvidou (2004) critisize the language of literary texts for being far from the conventions of Standard English established for the different levels of the students. That is probably the reason why students often feel that literary language "does not stick to the most common usages, but exploits and even distorts the accepted conventions in fresh and unexpected ways" (Lazar, 1993: 115.) According to Lima, also, the mastering of grammatical forms and graded structures that ususally guide the EFL teaching "clashes violently with the intentional bending and breaking of grammatical rules that seems to be one of the main features of literature" (Lima, 2005: 186). Lexis happens to reveal the same problem: unrestricted, creative use of lexical items "might hamper understanding instead of providing practical 
examples" (Lima, 2005:186). As Widdowson (1982) states, literature can provide 'misleading models' and this disruptive use of language, stimulating and refreshing for native speakers, might lead to possible confusions in case of FL learners.

Cultural issues also result in some problems when it comes to the use of literary texts in EFL. According to McKay (2001), literature is saturated with cultural concepts that might frustrate the unexperienced reader. For Duff and Maley (1990), cultural factors might present difficulties to the point of making it clearly impossible for an outsider to fully understand and share the scope of references of an insider. "Undeserible cultural connotations" conveyed by some literary texts might also restrain the use of certain texts(Collie \& Slater, 1987: 2). Especially when there is no agreement among language teachers and designers of materials on the question of the culture-L1 Vs. L2-EFL students should be exposed to. Some authors (Tomlinson, 2001) stand for including interesting L1 topics and themes as a way to humanize English textobooks while others (Brown, 2007) consider language to be a part of culture and defend L2 culture as an essential component of the EFL teaching program. In this sense, Lima (2005) observes that even in the case that teachers may feel determined to include L2 cultural elements in their EFL classes, these can often present a distorted reality.

Text selection is another difficult task for both teachers and students. A number of different factors such as learners' "language proficiency, age, gender, and background knowledge" (Khatib, Rezaei, Derakhshan, 2011: 204) should be taken into consideration when choosing a text. These factors are important as far as "teachers' desire to provide students with a literary experience may also result in a source of conflict simply because students do not have the linguistic, literary and cultural competence to tackle the text" (Lima, 2005: 186).

The length of the text is also considered by some scholars one of the major difficulties. If most of the students feel frightened to have to work with long texts, there are also some others who find shorter texts more difficult to handle with when "they do not offer extended contextual support and repetition which longer texts do" (Duff \& Maley, 1990: 7). Besides, there are language teachers who point to a fifth problem when they conclude that in higher education academic settings or specialized fields, where educational goals are given priority over aesthetic values, "literature has little or none capacity to serve the needs of learners" (Khatib, Rezaei, \& Derakhshan, 2011: 204). Other scholars, though, argue for literature as a motivating tool for instigating the learners to explore different text types, even if not directly meeting the EFL demands for Higher Education (Maley, 1989). All in all, some other scholars state that literature can be successfully integrated in content-based instruction classes (Shang, 2006).

\section{Methodological approaches to literature teaching: How to use literary texts}

Though most scholars (Duff, Maley, 1990; Langer, 1997; Ghosn, 2002; Erkaya, 2005; Khatib, Rezaei, Derakhshan, 2011) admit the multiple advantages of literature in the field of language teaching, consensus on the implementation of literary texts in the EFL classroom is still far from being reached. Possible causes are to be found in the existing uncertainty about the role of literature in the English language classroom, as much as in the multiplicity of theories on literature teaching and assessment. It is difficult to think of a universal way to introduce literary texts in the EFL classroom that would fit every single teacher's needs and interests. Some teachers prioritize grammar and vocabulary while others put the emphasis on the stylistic features, still leaving a niche to be filled in the field to those who consider it especially attractive to work with students' personal experiences. Other key factors to be equally considered are the linguistic competence of the students, the socio-cultural context of the learning process, the characteristics of the literary text used in the classroom, or the learners' specific needs.

A work of literature can be approached in a number of ways. An understanding of these approaches is crucial for teachers to determine the best way "to use the resources provided by literary texts with the purpose of improving language learning programs" (Bagherkazemi, Alemi, 2010:4). Some of the most important approaches to teaching literature in the EFL classroom are summarized in the 5.1 section of the present paper, immediately following. These approaches considered, section 5.2 is aimed at presenting an integrative approach to literature teaching in the EFL classroom.

\subsection{Main approaches to teaching literature in the EFL classroom}

An understanding of the already existing approaches to teaching literature in the EFL classroom is essential for teachers and educators to decide on the best way to use literature as a tool. Since a generally accepted categorization is still missing, the following subsections of the present paper (5.1.a; 5.1.b; 5.1.c; 5.1.d; 5.1. e) constitute an attempt at summarizing the different approaches that have become especially relevant in the recent years.

\subsubsection{Wellek and Warren (1984).}

Wellek and Warren (1984) distinguish between intrinsic and extrinsic approaches to literature. The first focuses specifically on the text while the second seeks to go deeper into the social, political or historical events which constitute the framework of the text. The intrinsic approach organizes texts into the following levels:

i. The grammatical level: organization of units of expression at both sentential and discursive levels.

ii. The lexical level: denotations and connotations of words also covering register, style, figurative language, etc.

iii. The structural level: narrative, argumentative and symbolic features describing rhyme, rhythm, cohesion and coherence at the discursive level. 
iv. The cultural level: transmission of messages from the texts to the readers and their relevance in a particular socio-cultural context.

Among the most important extrinsic factors claimed by the authors are the following:

i. The biographical factor: information about the author is an extrinsic element which affects literature. Authors live in a particular time and place and write their texts in a specific moment of their lives, at times for special occasions.

ii. The historical factor: texts mirror historical movements and economic, political, social and/or ideological processes.

iii. The aesthetic factor: texts reveal aesthetic devices according to the time and the artistic movement they belong to.

iv. The philosophical factor: texts illustrate topics that belong to a diversity of disciplines including ethics, psychology, theology, and even sciences or mathematics, among others.

As summarized in Figure 2 below, the extrinsic approach deals with readers' contribution to text interpretation while the intrinsic levels are aimed at the written, linguistic side of literary texts.

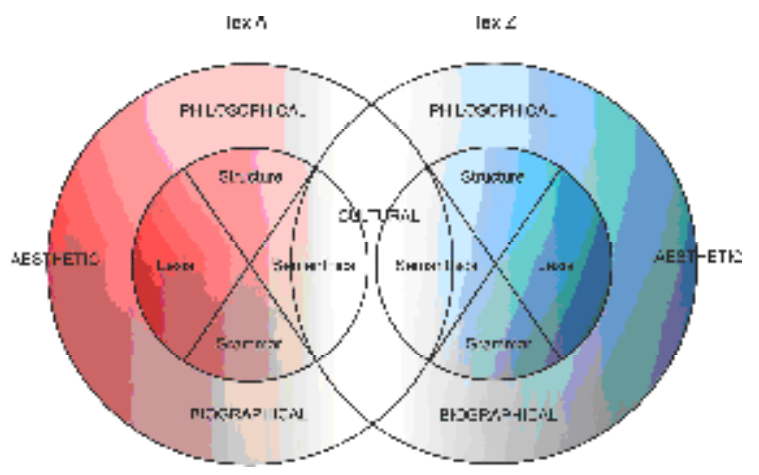

Figure 2. Adapted from Approaches to the study of literature: a practitioner's view (Moody, 1984)

\subsubsection{Maley's (1989).}

A general categorization of approaches to teaching literature is provided by Maley (1989) who distinguishes between i) "the study of literature" as a cultural artifact and ii) "the use of literature as a resource for language learning". At the same time, the author subdivides these approaches into i) "the critical literary approach" and ii) "the stylistic approach":

i) The critical literary approach mainly focuses on the literariness of the texts, including such features as motivation, characterization, background, etc. This approach assumes an advanced level of language proficiency and familiarity with the literary conventions.

ii) The stylistic approach is focused on literature, with the text aimed at students' mastering of their ability to describe and analyze the literary language.

As stated by Maley (1989), the critical approach demands highly specific linguistic background knowledge while the stylistic is mainly focused on linguistic competence and does not cover all of the teaching needs, especially those related to the development of the four language skills. The author opts for a mid-approach that posits no dichotomy between language and literature, this considered to be one of the many resources available for language teaching (Khatib, Rezaei, \& Derakhshan, 2011). This mid-approach, the author states, would generate a greater motivation and engagement with the text as well as the learners' increasing awareness of the language functions thanks to their interaction with the text (Maley, 1989).

\subsubsection{Carter \& Long (1991).}

Carter and Long (1991) defend three main models for literature teaching which they especially design so as to make literature fit in the EFL programs: i) the cultural model, ii) the language model and the iii) personal growth model. That is to say, they develop Maley's classification and add a third perspective to the system initially proposed:

i) The Cultural Approach considers literature as an ideal vehicle to transmit cultural notions such as history, literary theories, genres, biography of the different authors, etc. (Carter \& Long, 1991). Language is treated as a cultural artifact, requiring learners to approach literary texts from social, political, literary and historical perspectives.

ii) The Language Approach goes quite in the Light of Maley's Stylistic Approach. This model considers literature to be aimed at language development and awareness. Literary texts are seen as a wide source of contextualized linguistic features that can be systematically implemented through a wide range of activities. No attention is given to the literary quality of the texts. 
iii) The Personal Growth Approach gives priority to personal experience as a means to engage students in the reading process (Carter, \& Long, 1991). Learners' interaction with literary texts is intended to enhance their personal development and language awareness. (Carter \& Long, 1991)

According to Savvidou (2004), the Cultural Approach has fallen out in disuse due to its teacher-centered nature. The Language Approach is also highly criticized by the scholar as it does not allow exploring the possibilities literary texts offer to the reader. She argues for an integrated model that would include the components of all three approaches.

\subsubsection{Lima (2005).}

Following Carter \& Long's (1991) classification, Lima (2005) defends two main approaches to teaching literature: i) intuitive analysis and ii) syntactic analysis. These two approaches are quite similar to Carter \& Long's Personal Growth and Language Approaches. Hence literary and cultural aspects of the texts are put aside, giving preference to such phenomena as language organization and readers' responses.

i) Intuitive analysis focuses on readers' spontaneous response to the text, demystifying literature and connecting it to individual experience, (Lima, 2005).

ii) Syntactic analysis explores the linguistic organization of the text, that is to say; it shows how what is said is said and how meanings are made.

Lima pays special attention to the linguistic organization of the text since syntax is the "basis from which students can proceed to decode the text and construct its meaning" (Lima, 2005: 186). In combination with an intuitive analysis, though, this syntactic approach can also prevent students' uninformed responses to texts. This fact makes intuition worth of research on EFL, as a means of completing and revising initial interpretations.

\subsubsection{Van (2009).}

Together with the theories on the issue of literature teaching in the EFL classroom analyzed already, Van's classification goes more in consonance with the approaches to the analysis of literary fiction itself (2009). The six approaches described by the author include the following: i) New Criticism, ii) Structuralism, iii) The Stylistic Approach, iv) The Reader Response Approach, v) The Language Based Approach, and vi) The Critical Literacy Approach.

i) New Criticism appeared in the United States after the World War I and defended that meaning is contained solely in the text so that external elements are not to be taken into consideration. Following Thomson (1992), the world of a literary work is here presented as self-contained and to be objectively interpreted by readers. Contextual factors such as the political, social, or historical background of the text, along with the readers' reactions to the author's intentions, are disregarded as no relevant to the interpretation of the literary work.

ii) Structuralism gained importance in the $1950 \mathrm{~s}$ and did not treat literary texts as individual entities; instead, this trend tried to make them fit into a more global framework that could be applied to general literature (Dias \& Hayhoe, 1988). In other words, Structuralism was only interested in the mechanical, formal relationships of the literary and linguistic components of the text. Taking literature as a scientific system, Structuralism did not contribute to students' personal development, enhancement of cultural awareness, and development of language skills.

iii) The Stylistic approach, which emerged in the late 1970s, aimed at the analysis of the features of literary language to develop students' sensitivity to literature. This included the unconventional structure of literature, especially poetry, where language is often used in a non-grammatical kind of loose manner. (Van, 2009). Students are encouraged to use their linguistic knowledge to make aesthetic judgments and interpretations of the texts. In contrast to New Criticism and Structuralism, learners' personal judgments and interpretations of the text become highly desirable in this Stylistic approach.

iv) The Reader-Response approach highlights the role of the reader as a process-oriented approach to reading literature that leads to the reader/text interaction. It also enhances student-readers' drawing on their own experiences, opinions and feelings for their personal interpretation of literature. In contrast with the previous approaches, learners are here expected to play an active role in the reading process.

v) The Language-Based approach emphasizes awareness of the language of literature and calls for the implementation of a variety of language activities since it defends literature as "an excellent vehicle for CLT methods that result in four-skill English language development through interaction, collaboration, peer teaching, and student independence" (Van, 2009). Some activities to be implemented according to this approach include brainstorming, ending rewriting or plot summarizing, cloze tests, and jigsaw readings. Considering literature as an excellent tool to work on the basic language skills, this approach is often considered to be more accessible than other ones. (Carter, Long, 1991; Littlewood, 1986).

vi) Critical Literacy takes roots in a variety of theories such as critical philosophy, pedagogy, educational sociology, and feminism. Though not being initially developed as an approach to teaching literature, Critical Literacy is still very important as far as it reveals the relationship between language use and 
social power, and thus facilitates students' critical awareness of the role of language in social and power relations. That is to say, students' consciousness of how texts are related to issues of identity, culture, political power, gender, ethnicity, class, and religion.

According to Van, New Criticism and Structuralism have fallen in disuse because of their interest in the study of the formal elements of the text, leaving the individual and the subjective meanings behind. In the case of New Criticism, the study of literary terms is an end in itself, making it impossible to look "at the connections between the text and the readers' experiences" (Thomson, 1992). Structuralism, on the other hand, gives priority to the purely formal components of the literary text, not focusing on its cultural, social or ideological aspects. However, Van (2009) describes the Stylistic, Reader-Response, Language-based and Critical Literacy approaches as valid for the EFL context. When it comes to the Stylistic Approach, though, some problems might include the lack of ability to recognize irony in the literature of a foreign culture (Ramsaran, 1983) or the lack of experience and sensitivity to a variety of registers in everyday life contexts (Trengove, 1983). Similarly, some of the limitations of the Reader-Response approach include a problematic response of students' interpretations, as they might deviate from the original work and the lack of linguistic guidance for the selection of appropriate materials (Van, 2009). With regards to the Critical Literacy approach, Van (2009) affirms that this method would not work with students who were raised in societies with a limited amount of freedom of speech given that "some texts can affect students' sense of security and thereby hinder their involvement in class" (p.8).

\subsection{Towards an Integrative approach to literature teaching}

Most scholars indicate that none of the approaches to literature teaching in the EFL classroom of the ones mentioned above is complete enough to be implemented independently. Maley (1989) looks for a balance and defends the combination of the Critical Literary Approach with the Stylistic. Lima (2005) advocates for the fusion of Intuitive and Syntactic analysis to guarantee learners' motivation. Van's proposal (2009) includes key elements of four different approaches: Stylistics, Reader-Response, Language-based and Critical Literacy. Not surprisingly, the last decade development of the EFL methodology in the area of literature teaching tries to combine different approaches to enhance the use of literature as an effective tool in language acquisition.

Generally speaking, the last few decades reveal a clear shift from the solely linguistic analysis to a deeper concern with fostering inter-cultural awareness, appreciating learners' interpretations and responses to texts, and developing the ability to see "with different eyes" (Oster, 1989: 85). More specifically, the last decade has seen several attempts to develop an integrative model towards literature teaching that would include the linguistic, cultural and personal elements. Worldwide linguistis and language teachers Timuchin (2001), Savvvidou (2004), Divsar (2009), and Dhanapal (2010) have thus questioned the traditional use of literature in the EFL classroom, offering a new and fresher integrated look at the way in which literary texts might be incorporated into the language classroom. Their approaches to literature teaching go as follows:

\subsubsection{Timucin's Integrative Approach (2001).}

Timucin's (2001) case study deals with Turkish undergraduate students in the EFL classroom and questions the traditional systematic approach to literature teaching at Tertiary levels on the basis that this makes students extremely "dependent on teachers, books or exam-guides intended to the memorization of texts for instrumental purposes" (Timucin, 2001: 272). Having used an integrated approach comprising the language-based and the stylistic approaches into one single pedagogical framework, the author defends the positive impact of his proposed approach in terms of students' motivation, involvement, and appreciation of the literary texts.

\subsubsection{Savvidou's (2004) and Divsar's (2009) Integrated Approaches.}

Savvidou's (2004) and Divsar's (2009) integrated approaches defend the linguistic description of literary texts. Also, they aim at exploring literary and non-literary texts from the perspective of style and its relationship with content and form (Divsar \& Tahriri, 2009). That is to say, they suggest models that integrate linguistic description and textual analysis. Thus, the Savvidou's (2004) approach consists of a six-stage based model that makes literary texts work for language learning purposes:

The first stage-Preparation and Anticipation-elicits the learners' real or literary experience of the main themes and context of text

i. During the second stage-Focusing-learners get familiarized with the text through its listening and/or reading and are finally ready to focus on specific content in the text.

ii. The third stage-Preliminary Response-aims at developing the students' initial response to the text: written or spoken.

iii. The fourth stage-Working I-focuses on comprehending the first level of meaning through the practice of intensive reading.

iv. Meanwhile, the fifth level-Working II-leads to a deeper exploration of the way in which the message is conveyed through the overall structure of the text. Any possible special uses of the language are also considered. 
v. Finally, the sixth stage-Interpretation and Personal Response-is focused on increasing textual understanding thus enhancing the enjoyment of the text and enabling learners to come to their own personal interpretation of the text.

Quite similarly, the integrated approach proposed by Divsar and Tahriri (2009) point to three main considerations to be taken in the EFL teaching process: linguistic, cultural and communicative. According to the authors, the linguistic considerations are to be taken as a prerequisite for the literary discussion. The linguistic analysis of the text should be followed by cultural considerations as they might help students to lower the fences separating them from the target culture. In the same way, the communicative considerations set up the conditions for a crucial part of language learning consisting in an active interpretation of the text's meaning.

\subsubsection{Dhanapal's (2010) Integrated Approach.}

Dhanapal's Integrated Approach (2010) was implemented in the context of Malaysian high schools to enhance the students' development of critical and creative thinking skills (CCTS). In fact, literature was selected out of many other subjects as a suitable foundation o inculcate CCTS mainly due to its diversity in terms of contents. Apart from the developing of reading skills, this approach seeked for fostering students' critical thinking skills and hence for providing them with opportunities to a better understanding of both themselves and their fellow human beings. In fact, Dhanapal's approach combines the main charactersitics of the Reader Response Approach and the Stylistic Analysis, thus contributing to turn the classroom into a site for interaction where students are made responsible for their own learning (Shakila, 2007). As shown in the graph below, the Integrated Approach is based on the active work with literary texts. Students are in a permanent relation with the texts, constructiong their own meanings to be later on justified through the analysis of textual stylistic details.

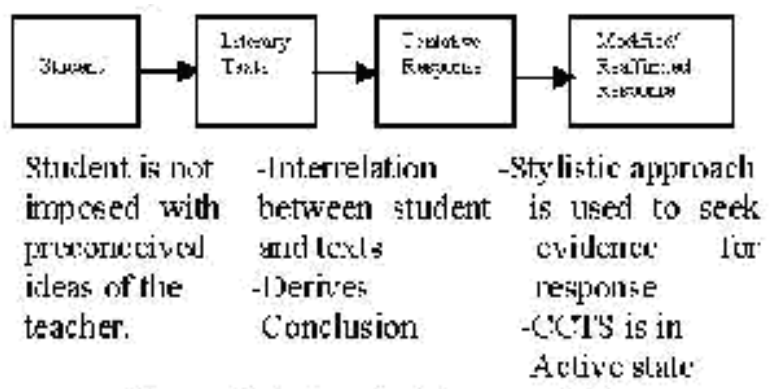

Figure 3. Integrated Aproach Process (Dhanapal, 2010)

\subsubsection{Tasmanian's Integrative Model (2012): Five Perspective Approach.}

The above-mentioned approaches are systematically reconciled in the Tasmanian Integrative Model for literature teaching, developed by an Australian group of scholars (Tasmanian Curriculum: Rationale, 2012). Though initially intended for L1 classes only, this could also make a promising model for EFL. In the Tasmanian Model, literary texts are to be approached not only from a linguistic point of view, but also from a social, cultural, and a literary perspective.

i. The Cultural Heritage Perspective supports the view that literature embodies the history, tradition, wisdom and beliefs of a particular society.

ii. The Language Skills Perspective considers students to work with texts for reading, writing, listening and speaking skill acquisition.

iii. The Personal Growth Perspective defends the idea that language learning is a holistic, natural process in which meaning is constantly built by students. This perspective is closely related to the Reader Response theory which supports the active role of the reader learners (Van, 2009).

iv. The Functional Perspective focuses on the analysis of the grammatical structures of language and the identification of the relation existing among language form, register, and context. .This also gives students control over a repertoire of language forms, and therefore over meaning-making and interpretation.

v. The Critical Literacy Perspective supports the view that texts are social constructs reflecting the beliefs and values of their time and culture, with multiple meanings conditioned by the structure of the discourse, the emphases and the omissions. They offer selected, partial versions of reality, producing, reproducing and maintaining different social ideologies. Working with literary texts is not only good for students to acquire the basic language skills, but also to explore the historical, cultural and social contexts in which texts are created and interpreted. This contributes positively to their personal and psychological evolution. As claimed by the authors of the Tasmanian model, (Tasmanian Curriculum: Rationale, 2012) the language learning process undertaken by the students of English entails learning experiences as the following: examining the embedded ideologies of texts and considering the ways in which they are constructed, positioned and manipulated, and also analyzing the power of language or 
writing texts which work for equity and change. All these experiences enable students to develop their interpretation skills, as well as to operate powerfully and for social justice with the real world.

\section{Literature and language teaching: some empirical research}

The ever-growing interest towards the use of literature and literary texts in the EFL classroom is undeniable. Researches and educators (Hanauer, 2001, Frantzen, 2002, Carter, 2007, Carroli, 2008) are finally coming to consider literature as an efficient tool that can provide EFL learners with opportunities to develop different aspects of the English language proficiency, as well as to deepen their knowledge and understanding of English culture.

The acknowledgment of the value of the use of literature for the language classroom does not mean that teachers have reached a consensus in terms of how to implement literature in their classrooms, what kind of texts they should use, or when is the best moment to start using literary texts. In fact, there is still controversy concerning these issues among language teachers and educators. Even the role and the relevance of literature for language learning itself are still being questioned by some linguists (Edmonson, 1997). One of the main problems in this sense comes given by the lack of empirical research on this issue. However, both the supporters of the use of literature in language education (Shanahan, 1997; Hanauer, 2001) and its opponents (Edmonson, 1997) seem to agree on the fact that more empirical research is necessary in order to validate the theoretical positions and to support the use of literature in the language classroom.

Carter (2007) speaks about the general "absence of empirical classroom-based research", and the necessity of generating "enhanced paradigms for greater empirical investigation" (p.11). Also Edmondson (1997) claims the need for "coneptual clarity regarding which role or roles foreign language literature can or should play" (p.44) in language teaching, and points out the paucity of empirical research in this area. The lack of "actual empirical data related to the reading and comprehension of literature within language classroom" is also questioned by Hauner (2001: 295). Meanwhile, Carroli (2008) comments the scare presence of empirical investigations analyzing students' perception of literature and this context, as well as its impact on them. Only a few current studies, according to this author, have explored the role of literature in the L2 curriculum from the students' point of view.

Though research is still rather scarce, the recent years have been marked by the increase of empirical investigation in this area (Paran A. , 2008). Among few current studies that have explored the role of literature in the L2 and EFL curriculum the following ones are to be mentioned:

i. Hauner (2001) analyzed the role of the poetry reading task for foreign language learning. The study involved twenty female university students, registered in a teacher training course in Israel. None of the participants had degrees in English or Hebrew literature. The results of the study were clearly positive, categorizing the task of poetry reading as a useful technique in the foreign language classroom when working with advanced learners. As the author states, poetry-reading can facilitate the development of both linguistic and cultural knowledge of the target language.

ii. Butler (2006) provides an example of an attempt to incorportae literature into language classes in a South African context. The English course he describes, implemented in the context of the University of North West, included four components: Introduction to English Studies, Introduction to Textual Analysis, Introduction to Literary Genres and Grammar Awarness. Based on the integrated approach between language and literature elements, the course resulted to be evaluated in a highly positive way (with $86 \%$ of students in favour of the integrated approach).

iii. Minkoff (2006) tries to justify the role of an elective literature and language course for students majoring in business management. Using Barnes's (1991) book Talking it Over to illustrate his approach, the author describes the structure of the lessons and offers an overall evaluation of the experiemnt. Suprisingly, most of the students evaluated the course as a great success in spite of the fact that business students might initially seem to have had little need to acquire a literature background knowledge.

iv. The study conducted by Lin (2006) is set in a secondary school in Singapore, where English is the second language for most of the students and language and literature are usually taught as separate subjects. The author claims for the pedagogical need to embed literature into a larger framework of language classes. According to Lin (ibid.) those teachers following this approach reported to have had highly positive results.

v. Bilal Anwar and Khan Rana (2010) provide the data of an empirical investigation conducted in the context of Pakistan with 280 university students enrolled in different English language and Literature courses. After having analyzed the students' responses to the questionnaires that had been previously administered, the authors reported that most of the students considered literature as a helpful component in language studies and as an effective source to be used in the language class.

It is important to notice that classroom interaction can be also explored through the testimony of teachers, reflecting their daily work (Paran, 2008). This kind of experiences might be especially valuable, taking into consideration that they might not be just a separate experience, but a whole experimentation with literature in the classroom. Thus Lattimer (2003) provides six models to work with different literary genres; Cranston (2003) offers a large number of quick snapshots of different lessons in which she used poetry; Rosenkjar (Rosenkjar, 2006) shares a stylistic-based approach to the analysis of a poem with the intended readership; Hess (2006) offers a description of lessons based on working with short stories and integrating the use of four skills; Völz (2001) provides an account of his use of short fiction by the same writer over the years; Diaz-Santos (2000) focuses on a personal three and a half years' experience of 
using technothrillers in the classroom. Definitely, all of them contribute to documenting the activity of language teachers who experiment with literature.

\section{Conclusions}

The success in the acquisition of a language is often determined by the students' interest and enthusiasm for the material used in the language classroom, the level of their persistence with the learning task, and the level of their concentration and enjoyment (Crookes and Schmidt, 1991). This type of students' personal involvement might come from the material and lessons used in the classroom. In this article we have tried to show that literature, when used properly, can be an effective tool for developing foreign language skills. We have also tried to demonstrate that current research is being active in terms of showing the multiple benefits of using literature in the language classroom. This leads us to more easily refute the arguments of those scholars who are against the use of literature as a tool for language teaching (such as Edmondson, 1997).

There are still key issues that need to be object of study. We still need more empirical research to i) validate some new approaches to the integration of literature in a language classroom and to ii) know the learners' response to have to read literature in a foreign language. Also, more systematic evaluation of different language courses based on literature components as well as more systematic research on the students' perspective are equally needed. All in all, though, it is clear that literature has a lot to offer to the language learner. There are evidences demonstrating that it provides a motivating drive for language learning and teaching due to its spectacular features not readily found in any other types of texts. However, if considering the points of controversy of literature-as-a-language tool posed in this article, it is to be said that there is no one single right way to use literature in the language classroom. In fact, various approaches can be adopted by a particular teacher depending on his/her teaching needs. We hope that the ideas here presented will facilitate teachers' effective use of literature to improve English instruction.

\section{References}

Alderson,C. (2000). Assessing Reading. Cambridge:CUP.

Arens, K., Swaffar, J. (2000). Reading goals and the standarts for foregn language learning. Foreign Language Annals (33), 104-122.

Averil, J. (2001). The rhetoric of emotion, with a note on what makes great literature great. Empirical Studies of the Arts, 19 (1), 5-26.

Bagherkazemi M., Alemi, M. (2010). Literature in the EFL/ESL classroom: Consensus and controversy. LiBRI. Linguistic and Literary Broad Research and Innovation, 1 (1), 1-12.

Barnes, J. (1991). Talking It Over. London: Picador.

Belcher, D. \& Hirvela, A. (2000). Literature and L2 composition: Revisiting the debate. Journal of Second Language Writing, 1 (9), 21-39.

Bilai Anwar, R., \& Khan Rana, A. (2010). Perceptive Study "Teaching English Literature through English Language". Saarbrucken: Lambert Academic Publishing.

Brown, H. D. (2007). Principles of Language Learning and Teaching. New York: Pearson Education.

Brumfit, C. J. and Carter, R. A. (1986). Literature and Language Teaching. Oxford: Oxford University Press.

Butler, I. (2006). A brighter future? Integrating and for -year. In A. Paran (ed.), Literature in language teaching and learning (pp.11-25). Virginia: TESOL.

Carroli, P. (2008). Literature in Second Language Education. London and New York: Continuum.

Carroli, P. (2002). Perceptions of literature: a comparasion of students'and educators' views. Proceedings of Innovations in Italian teaching workshop (pp.113-128). Griffith: Griffith University.

Carter, R. (2007). Literature and language teaching 1986-2006: a review. International Journal of Applied Linguistics, 17 (1), 3-13.

Carter, R.A. \& Long, M.N. (1991). Teaching Literature. London: Longman.

Collie, J. \& Slater, S. (1987). Literature in the Language Classroom: a Resource Book of Ideas and Activities. Cambridge: CUP.

Cook, G. (1998). Literature and cultural studies. Which is it to be? Literature, Media and Cultural Studies Newslatter. (16).

Cook, G. (1994). Discourse and Literature: The Interplay of Form and Mind. Oxford: OUP.

Crook, G., Schmidt, R. 1991. Motivation: Reopening the research agenda. Language Learning, 41 (4): $469-512$.

DeBlase, G. (2005). Teaching Literature and Language through Guided Discovery and Informal Classroom Drama. English Journal, 95 (1), 29-32.

Dhanapal, S. (2010). Stylistics and reader response: An integrated approach to the teaching of literary texts. Literacy Information and Computer Education Journal, 1 (4), 233-240. 
Divsar, H., Tahriri, A. (2009). Investigating the Effectivness of an Integrated Approach to Teaching Literature in an EFL Context. Pan-Pascific Association of Applied Linguistics, 2 (13), 105-116.

Duff, A., Maley, A. (1990). Literature. Oxford: Oxford University Press.

Dupuy, B. (2000). Content-based instruction: Can it help ease the transition from beginning to advanced foregn language classes? Foreign Language Annals (33), 205-223.

Edmonson, W. (1997). The role of literature in foreign language learning and teaching: some valid assumptions and invalid arguments. Applied Linguistics Across Disciplines. AILA Rewiew, special issue, 42-45.

Elliot, R. (1990). Encouraging Reader-Response in ESL Situations. ELT Journal (44), 191-198.

Erkaya, O. R. (2005). Benefits of using short stories in the EFL Context. Asian EFL Journal (8), 1-13.

Floris, D. (2004). The Power of Literature in EFL Classrooms. K@TA 2,6 (1), 1-12.

Foreign Languages and Higher Education: New Structures for a Changed World (2007). Retrieved from http://www.mla.org/pdf/forlang_news_pdf.pdf.

Frantzen, D. (2002). Rethinking foreign language literature: Towards an integration of literature and language at all levels. En V. Scott, \& H. Tucker (ed.), SLA and the Literature Classroom: Fostering Dialogues (pp.109-130). Boston: Heinle\&Heinle.

Gajdusek, L. (1988). Toward wider use of literature in ESL: Why and how. TESOL Quarterly (22), 227-254.

Ghosn, I. (2002). Four good reasons to use literature in primary school ELT. ELT Journal, 2 (56), 172-179.

Gilroy-Scott, N. (1983). Teaching Literature Overseas: Language-Base Approaches. Oxford: Pergamon Press.

Hanauer, D. (2001). Focus-On-Cultural understanding: Literary reading in the second language classroom. CAUCE, Revista de Filología y Didáctica (24), 389-404.

Hanauer, D. (2001). The task of poetry reading and second language learning. Applied linguistics, 295-323.

Hess, K. (1999). Poetry as an Intercultural Peace Bridge for Teaching ESL. Alberta: University of Alberta Press.

Horner, S. (1983). Best Laid Plans: English Teachers at Work for School Council. York: Longman.

Hur, H. (2005). Literature-based Activities and Language Socialization in an Elementary ESL Classroom. University Park: The Pennsylvania State University.

Kern, R. (2000). Literacy and Language Teaching. Oxford: Oxford University Press.

Khatib, M., Rezaei, R., Derakhshan, A. (2011). Literature in the EFL/ESL classroom. English Language Teaching, 4 (1), 201-208.

Kramsch, C. (1993). Context and Culture in Language Teaching. Oxford: OUP.

Kramsch, C. \& O. Kramsch (2000). The avatars of literature in language study. The Modern Language Journal 84 (1), 553-573.

Kramsch, C. (2013). Culture in Foreign Language Teaching. Iranian Journal of Language Teaching Research , 1 (1), $57-78$.

Langer, J. (1997). Literacy acquisition through literature. Journal of Adolescent and Adult Literacy (40), 602-614.

Lazar, G. (1993). Literature and Language Teaching. Cambridge: CUP.

Lee, J. (1986). Findings and Implications of L2 Reading Research. Hispania (69 ), 181-187.

Lima, C. (2005). Is the rest silence ... ? IATEFL (186). Retrieved from http://www.iatefl.org/iatefl/iatefl-voices.

Liddicoat, A. C. (Ed.). (2000). Teaching Languages, Teaching Cultures. Melbourne: Language Australia.

Lima, C. (2010). Selecting Literary Texts for Language Learning. Journal of NELTA, 15 (1-2), 110-114.

Lin, B. (2006). Exploring the literary text through grammar and the re-integration of literature and language teaching. In A. Paran (ed.), Literature in language teaching and learning (pp.146-151). Virginia: TESOL.

Lin, B. (2006). Genre-based teaching and Vygotskian principes in EFL: The case of a university writing course. Asian EFL Journal, 8 (3).

Littlewood, W. T. (1986). Literature in the school foreign-language course. In C. J. Brumfit and R. A. Carter (ed.), Literature and language teaching (pp.177-83). Oxford: Oxford University Press.

Llach, P. A. (2007). Teaching language through literature: the waste land in the esl classroom. Odisea (8), 7-17.

MacKenzie, I. (2000). Institutionalized utterances, literature, and language teaching. Language and Literature (9), 6178.

Maley, A. (1989). Down from the Pedestal: Literature as Resource. In Literature and the Learner: Methodological Approaches. Cambridge: Modern English Publications.

McKay, S. (2001). Literature as content for ESL/EFL. In M. Celce-Murcia, Teaching English as a second or foreign language (pp. 319-332). Boston: Heinle\&Heinle. 
Minkoff, P. (2006). Talking it over in class. In A. Paran (ed.), Literature in language teaching and learning. Virginia: TESOL.

Nasr, N. (2001). The use of poetry in TEFL: Literature in the new Lebanese curriculum. Revista de Filología y su Didáctica (24), 345-363.

O'Brien, T. (1999). A suggested model for teaching literature. In M. Ed, Course Notes. Manchester: University of Manchester.

Paran, A. (2006). Literature in language teachig and learning. Virginia: TESOL.

Paran, A. (2008). The role of literature in instructed foreign language learning and teaching: An evidence-based survey. Language Teaching , 41 (4), 465-496.

Ramsaran, S. (1983). Stress, rhythm and intonation in the study of English literature. In C. J. Brumfit (ed.), Teaching literature overseas: Language-based approaches (pp.85-102). Elmsford, NY: Pergamon.

Rice, D. (1991). Language proficiency and textual theory: How the train might meet. ADFL Bulletin, 22(3), 12-15.

Rosenkjar, P. (2006). Learning and teachinh how a poem means: Literary stylistics for EFL undergraduates and language teachers in Japan. In A. Paran (ed.), Literature in language teaching and learning (pp.117-131). Virginia: TESOL.

Savvidou, C. (2004). An integrated approach to the teaching of literature in the EFL classroom. The Internet TESL Journal (12).

Shakila A. M. (2007). A stylistic approach. In G. Subramaniam (ed.), Approaches to teaching literature: theory and practice (pp. 50-78). Petaling Jaya: Sasbadi Sdn. Bhd.

Shanahan, D. (1997). Articulating the relationship between language, literature and culture:toward a new agenda for foreign language teachibg and research. The Modern Language Journal, 81 (2), 164-174.

Shang, H. (2006). Content-based Instruction in the EFL Literature Curriculum. The Internet TESL Journal, 12 (11).

Stern, S. (1985). Teaching Literature in ESL/EFL: an Integrative Approach. Los Angeles: University of California.

Swaffar, J. (1999). The case for foreign languages as a discipline. ADFL Bulletin (30), 6-12.

Tayebipour, F. (2009). In Defence of Teaching literature to EFL students in the era of Globalization. En R. R. L. J. Zhang (ed.), Englishes and Literatures-in-English in a Globalised World: Proceedings of the 13th International Conference on English in Southeast Asia. (pp. 213-219). Singapore: National Institute od Education.

Thomson, J. (1992.). The significance and uses of contemporary literary theory for the teaching of literature. In J. Thomson, In Reconstructing literature teaching: New essays on the teaching of literature (pp.3-39). Norwood: Australia: Australian Association for the Teaching of English.

Timucin, M. (2001). Gaining insight into alternative teaching approaches employed in an EFL literature class. Revista de Filología y su Didáctica (24), 269-293.

Tomlinson, B. (2001). Humanizing the coursebooks. In B. Tomlinson (ed.), Materials development for language teaching. London: Continuum.

Topping, D. M. (1968). Linguistics or literature: an approach to language. TESOL Quarterly, 2 (2), 95-100.

Trengove, G. (1983). Language as a literary medium: An undergraduate course. In C. J. Brumfit (ed.), Teaching literature overseas: Language-based approaches (pp. 103-20). Elmsford, NY: Pergamon.

Van, T. (2009). The relevance of literary analysis to teaching literature in the EFL classroom. English Teaching Forum 2-9(3).

Vodickova, M. (2006). Paran, A. En S. I. Juliet (ed.), Literature in language teaching and learning. Virginia: TESOL. Widdowson, H. (1982). The Use of Literature. In M. Hines and W. Rutherford (ed.). On TESOL 81.Washington, D.C.: TESOL. 